APLICAÇÕES DA FOTOGRAFIA A CORES (PROCESSO LUMIERE EA FOTOGRAFIA NA MEDICINA
NA MARÍLIA PERES 


\section{pp. 54-71}

DOl: 10.24140/ijsim.v3.n1.04

ijsim.ulusofona.pt

(๑) 2019 BYNC

\section{A utilização da fotografia em Medicina} significados que, pelas palavras, se não conseguem

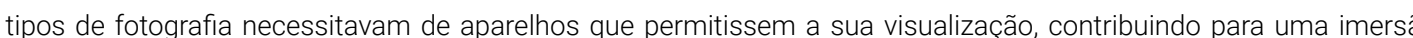
do observador no objeto observado. A juncão dos dois processos originou as imagens estereoscópicas a cores (autocromos estereoscópicos) que foram populares na época. Vistas com equipamento especial, elas produziam imagens em 3D que seduziam o observador do início do século XX. As fotografias estereoscópicas e os autocromos, longe de serem unicamente um instrumento de diversão ou artístico, desde cedo ocuparam um lugar primordial no desenvolvimento da medicina, bem como no seu ensino e divulgação. Através de uma abordagem histórica, pretende-se neste artigo analisar o papel destas duas técnicas fotográficas imersivas na medicina, de modo a sublinhar as semelhanças entre os dois processos, assim como conhecer as suas limitações.

\section{Palavras chave: Fotografia científica; estereoscopia; autocromos}

\section{Abstract}

What does stereoscopic photography have in common with color photography as developed by the Lumière brothers? Both processes are illusions, leading human perception to reconstruct the appearance of depth and natural color. Both types of photography required devices to enable observation, contributing to a visual immersion with the subject matter. The combination of both processes gave rise to coloured stereoscopic images ( stereo autochromes) which were popular in the period. When seen through special equipment, they could produce three-dimensional images which fascinated early 20th-century observers. Stereoscopic photography and autochromes were, rather than a simple means of entertainment and art, of paramount relevance to the development of medicine, as well as to its dissemination and medical education. Through an historical approach, this essay seeks to examine the role of these two immersive photographic techniques in medicine, thus allowing us to highlight the similarities between both processes, as well as to acknowledge their limitations.

Keywords: Scientific photography, stereoscopy, autochromes

\section{Peer Review:}

António Fernando Cascais, Universidade Nova de Lisboa, Portugal

Victor Flores, Universidade Lusófona de Humanidades e Tecnologias, Portugal
Todos olhámos, mas nunca vimos as imagens con que a ciência sempre se fez. Como se elas não estivessem lá. Como se elas não tivessem que ter estado lá. Sempre ao lado da palavra. Incapazes de falar por si só, mas necessariamente lá, como suporte de dizer. (POMBO, 2010, p. 11)

um atlas médico com reproduçōes dos micro-daguerreótipos (Fig. 1)

Sendo a Medicina uma área multidisciplinar, era expectável que a fotografia médica abrangesse desde cedo as várias especialidades, bem como as várias etapas dentro de um processo médico. Esta pode ser usada no diagnóstico, na comunicação entre pares e no ensino. Por outro lado, o objeto retratado pode ser um processo médico (por exemplo uma cirurgia), um paciente, partes do corpo humano, ou mesmo

No discurso que apresentou à Academia das Ciências em 1839 em Paris, François Arago considerou, com grande sentido de previsão, o contibuto que teriam tido de previsão, o contributo que teriam para as Ciências e
as Artes os trabalhos de Louis Daguerre e Joseph Niépce reas Artes os trabalhos de Louis Daguerre e Joseph Niépce re-
lativos à descoberta da Fotografia, realçando a sua utilização como um auxiliar indispensável ao cientista nas áreas da Astronomia, Arqueologia e Espetroscopia. Sucessivos progressos técnicos e científicos encorajaram a prática fotográfica ciências. No início a utilização da fotografia no papel de auxiliar documental da Ciência era entendida, segundo Jules Janssen (1824-1907), eminente astrónomo francês, como a "retina do cientista".

Foi logo em 1839, que o médico francês Alfred Donné (18011878), ajudado pelo seu assistente, o físico León Foucault (1819-1868), obteve fotomicrografias (daguerreótipos) de diversos fluidos humanos, incluindo glóbulos sanguíneos e mucos, utilizando o que ele designou "microscópio-daguerreotipo", com um helióstato acoplado ao microscópio, igualmente equipado com luz oxídrica. Donné foi pioneiro na aplicação da fotografia à microscopia usando o microscópio no ensino e investigação médica. Em 1845 Donné e Foucault, publicaram órgãos, tecidos ou fluidos (anatomia patológica e fotomicrografia). É também possível falar de fotografia médica, tendo como objeto de estudo os próprios atores, isto é, os médicos e outros técnicos de saúde, assim como as instituições.

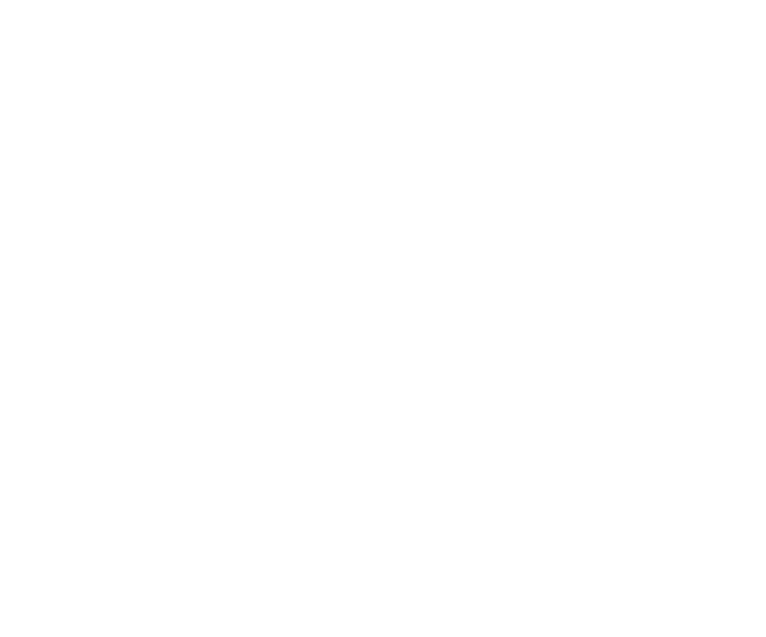
(Fonte: gallica.bnf.fr / Bibliothèque Nationale de France)
1. Daguerreótipo «Cristaux de la salive» por Léon Foucault em 18 
O valor do uso da fotografia na medicina é reconhecido universalmente, deixando de lado as consideraç̃oes sobre a manipulação para efeitos artísticos ou de falsificação. Apesar deste valor, a fotografia plana, dita normal, não mostra o objeto tal como os olhos o reconhecem, falhando por isso na tentativa de mostrar o real. Embora se associe a estereoscopia à fotografia, os estudos acerca da visão binocular são anteriores à invenção do estereoscópio. Contudo, será apenas no século XIX que a ciência se propôs a quantificar e precisar a diferença angular de cada olho para especificar a disparidade das imagens e tentar compreender como é que o olho é capaz de as sintetizar.

$\mathrm{O}$ conceito de estereoscopia foi desenvolvido pelo físico britânico Charles Wheatstone (1802-1875), que em 1832 inventou o primeiro estereoscópio. A sua invenção antecedeu a descoberta do daguerreótipo. Descrevendo o seu instrumento, Wheatstone propôs o nome 'estereoscópio' para indicar a sua propriedade de representar figuras sólidas (Wheatstone, 1838). Em 1849, o físico escocês David Brewster (17811868) exibiu um modelo de estereoscópio portátil, sugerindo que deveria ser aplicado a fotografia (Claudet, 2008). Em 1850, Brewster levou seu estereoscópio para Paris, onde Abbé Moigno (1804-1884) ficou muito impressionado com a ideia e a apresentou a um fabricante de instrumentos de óptica, Jules Duboscq (1817-1886), que sugeriu produzir imagens transparentes em vidro, substituindo o fundo sólido por uma placa de vidro. Na Grande Exposição de Londres em 1851, no Palácio de Cristal, foram exibidos vários visores estereoscópicos de Duboscq, bem como um conjunto de daguerreótipos estereoscópicos. Após o interesse demonstrado pela ralnha Victoria, o fascínio por este instrumento disseminou-se rapidamente. Na época, o estereoscópio tornou-se tão co-

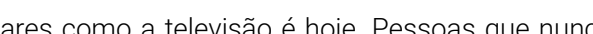
haviam tido a possibildade de viajor poljom conhecer, com todo o pormenor, paisagens ou monumentos. As imagens mesmo tempo mentos, paisagens, também se divulgava o conhecimento científico (Peres, 2016)

\section{Estereoscopia e Medicina}

A estereoscopia foi usada em muitas áreas da medicina destacando-se essencialmente nas áreas de Anatomia, oftalmo logia, Radiografia, Cirurgia e Dermatologia. Em 1905 foi publcada a 1 . $^{a}$ edição de um dos mais famosos atlas de anatomia The Edinburgh Stereoscopic Atlas of Anatomy de Cunningham Waterson, editado por Keystone View Co. \& Imperial Publishing Co, com cinco volumes de imagens estereoscópicas. As fotografias eram preparadas na Universidade de Edimbur go pelo Professor D. J. Cunningham, assistido pelo demons trador de Anatomia, D. Waterson, pelo cirurgião M. H. Cryner pelo especialista de olhos, nariz e ouvidos F. E. Neres. Os autores avaliavam a possibilidade de preservar as várias estruturas em formaldeído, e as dissecações eram efetuadas por médicos reconhecidos pela sua autoridade em anatomia. É possivel encontrar exemplares deste atlas em museus de medicina, em bibliotecas com espólios de escolas médicas ou mesmo em antigos liceus (Fig. 2 e 3). Em 1911 o Atlas á era composto por 10 volumes com 324 fotografias estereoscópicas.

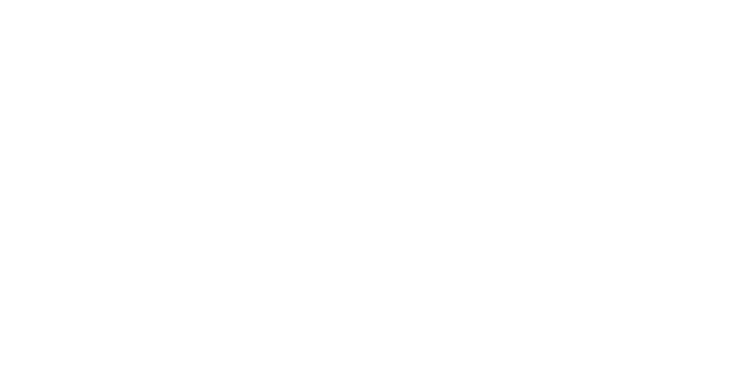

Fig. 2e Fig. 3. Estereoscópio modelo americano (de Holmes) e conjunto

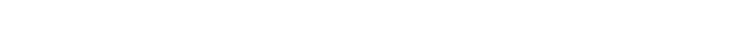
(Escola Secundária de Camões: ME/401109/93/94/95)

Em 1908, o medico francês Albert Monthus (1871-1948) publicou "Iconographie stéréoscopique oculaire (anatomie, clinique technique opératoire)" com 25 estereoscopias $(8 \times 16 \mathrm{~cm})$ e com explicações sobre cada uma delas (Fig. 4 e 5). Este connica Oftalmológica. Refere o autor: "A fotografia estereoscópica é um método de ensino admirável, uma vez que restitui, da melhor forma possivel, através da noção de relevo, a impressão da realidade.' " (Monthus, 1908: p. 7) 0 autor utiliza as estammia, de anatomia patológica e também de técnicas cirúrgicas. junto de fotografias era destinada aos alunos do curso de Clipas estereoscópicas para mostrar alguns exemplos de anato-

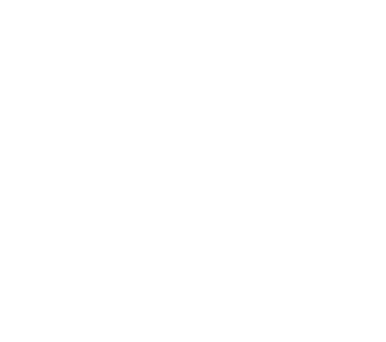

Fig. 4. Papiloma conjuntival' (Monthus, 1908, estampa XIII)

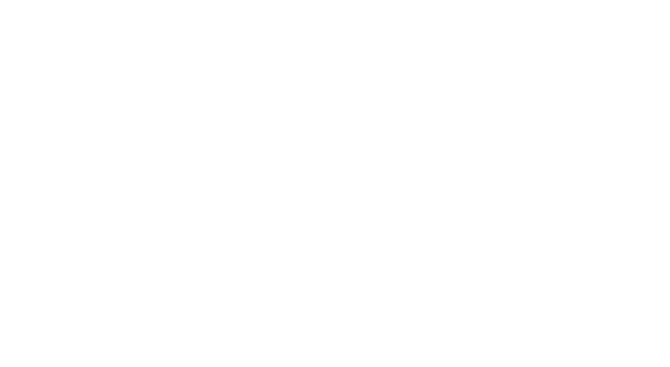

Fig. 5. Um caso de Exenteração² (Monthus, 1908, estampa XXV)

Uma importante aplicação da fotografia estereoscópica na medicina nasce com a descoberta dos raios $X$, por Roentgen 1895. Com a estereografia dos raios $X$ era possível localizar objetos, ou defeitos em corpos, podendo ser uma mais-valia em estudos de anatomia e cirúrgicos. Para a obtenção de uma radiografia não é necessário usar qualquer câmara fotográfica ou lente, e a necessária separação que se tem de ter para obter duas imagens estereoscópicas, de cerca de $65 \mathrm{~mm}$, pode ser conseguida movendo com precisão o objeto a radiografar ou o tubo de raios $X$.

1) O papiloma conjuntival e um tumor benigno do epitélio escamoso estratificado da conjuntiva, muito frequente,

A exenteraçăo orbitaria è un cirurgia radical realizada para casos de doenças neoplásicas, inflamatórias ou infecciosas avançadas, quando As procedimentos mais conservadores não são curativos. 


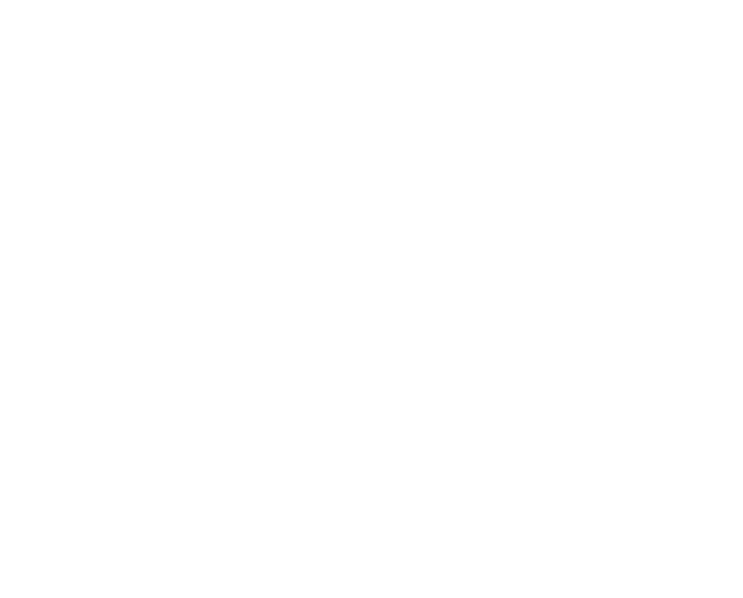
Fig. 6. Equipamento para obtencãa de radiografias estereoscópicas
(Kassabian, 1904)

Logo em 1896, Elihu Thomson publica Stereoscopic Roentgen Pictures, sugerindo a visualização de imagens estereoscópicas de raios X. Também E. Davidson (1898) insiste nas vantagens de usar a fotografia e a radiografia estereoscópica para documentar estados clínicos (Peres, 2016). Segundo Kassabian (1904), o método mais habitual para obter este tipo de fotografias estereoscópicas consistia em colocar o paciente deitado com um tubo de raio $X$ por baixo, e uma placa fluorescente por cima do corpo (Fig. 6). $O$ tubo de raios $X$ podia deslocar-se horizontalmente em várias direções obtendo-se deste modo as posições necessárias para o par de radiografias (Fig. 7).

Um outro método consistia em dispor de dois tubos de raios $X$ a trabalhar em simultâneo de modo a projetar num ecrã
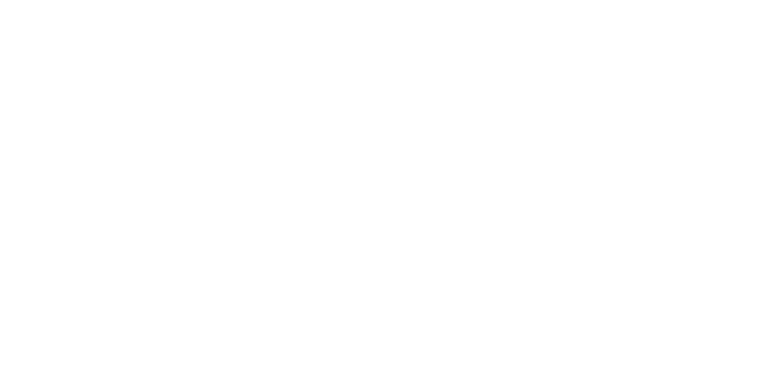
$6 \mathrm{~cm}$ (Kassabian, 1904)

fluorescente. Este ecrã assim iluminado poderia ser observado com um estéreo fluoroscópio.

A utilização do equipamento referido permitia a visualização de objetos estranhos no organismo humano, técnica ampla mente desenvolvida por Mackenzie Davidson, no Hostal Charing Cross, ou mesmo de angiografias estereoscópicas, obttdas por J. F Bergmann de Wiesbaden, em 1903. reoscópica teve uma maior disseminação. Apesar de serem comuns os teatros anatómicos, a utilização de cadáveres para o treino dos estudantes de medicina era muitas vezes difícl (Abreu, 2007). Por este motivo, a utilização da imagem fotográfica, principalmente a estereoscópica, vem introduzir um ado, em 1865 o cirurgião germânico Christian Theodor Billroth (1829-1894) $)^{3}$ publicou "Stereoscopische Photographien chirurgischer Kranken" com 12 provas estereoscópicas em albumina, coladas (Billroth, 1865). Algumas delas representam pacientes
Foi possivelmente na área da cirurgia que a fotografia este grande avanço no ensino das técnicas cirúrgicas. Por outro

3) Theodor Billroth foi um dos maiores cirurgiöes germânicos na história da medicina. Mencionado entre os pioneiros da cirurgia abdominal, deu seu próprio nome a uma intervenção de cirurgia gástrica que foi amplamente praticada em todo o mundo. Exerceu medicina em Zurique e

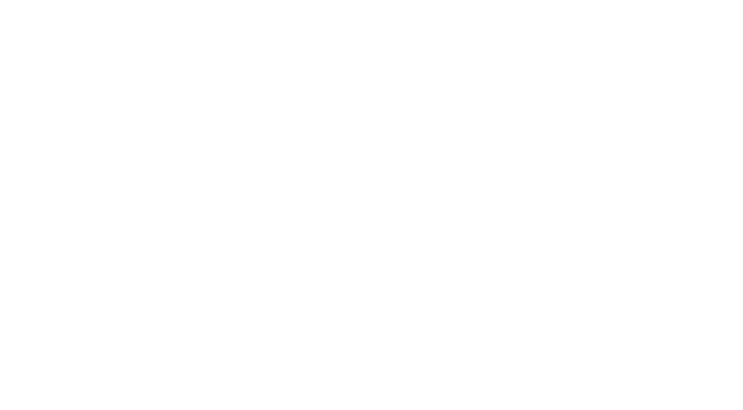

cópicas em albumina de um paciente após cirurgia (Billroth, 1865, folha 8)

com problemas ortopédicos e de pele, mostrando registos fotográficos de antes e de depois da cirurgia (Fig. 8)

Em 1909, o médico Howard Atwood Kelly (1858 -1943) publicou "The Stereo-Clinic"4. O primeiro volume contém 41 fotografias estereoscópicas representando vários tipos de cirurgias, passo a passo. As fotografias eram realizadas durante as $\mathrm{ci}$ rurgias por Max Broedel, conhecido como o pai da ilustração médica (Cullem, 1943). Cada fotografia estereoscópica era pre cedida por um texto contendo as explicações mais importantes. 0 livro era acompanhado por um estereoscópio Holmes.

Desde muito cedo que os dermatologistas usam a imagem como modo de comunicar com outros médicos ou estudantes de medicina. Após a invenção da fotografia, os atlas de dermatologia apresentavam texto e fotografias das dermatoses mais frequentes bem como alguns casos raros e interessantes. Também na área da dermatologia a utilização de imagens estereoscópicas a cores permitiu documentar a

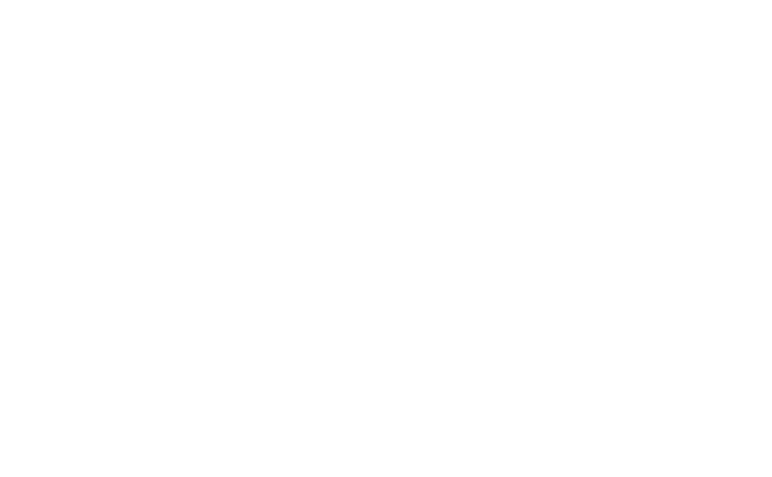

Fig. 9. Prova estereossópica de um paciente de dermatologia
"The Stereoscopic Skin Clinic" (Coleçẫo de M. Peres)

morfologia das lesões da derme de um modo muito mais real. Foi o caso do muito disseminado Atlas "The Stereoscopic Skin Clinic" publicado por S. I. Rainforth em 1910. As imagens este reoscópicas eram montadas num cartão (de $12,5 \times 17,5 \mathrm{~cm}$ ) (Fig. 9), acondicionadas numa caixa original e acompanhadas por um visor estereoscópico do tipo Holmes.

Este atlas, que teve várias edições, era composto por 130 ilustrações estereoscópicas coloridas e um texto sob a forma de uma descrição clínica (na parte de trás do cartão). Projetado para o uso de profissionais e estudantes de medicina, constituilu um verdadeiro inventário fotográfico de doenças de pele (do acne à síflis). As descrições detalhadas das doenças forneciam informação útil sobre as patologias da pele num momento em que os dermatologistas ainda eram raros.

Howard Kelly foi um dos fundadores do The Johns Hopkins Hospital. Trabalhou com o fotógrafo Max Brodel e posteriormente com Herman Becker e August Horm (Cullen, 1943) 


\section{O Processo do Autocromo dos irmãos Lumière}

No início do século XX surge o primeiro processo fotográfico em cor comercialmente viável, tendo sido patenteado pelos irmãos Auguste e Louis Lumière (Fig. 10), em França em 1903 e nos Estados Unidos da América em 1906, e comercializado a partir de 1907. Este é um processo de cor aditivo pois derivava douso de unstema de filros de cor que permitia criar uma imagem final a cores. O sistema de cor aditivo funciona pela adição das cores vermelho, verde e azul para obter uma imagem (no caso das placas autocromo pela justaposição de filtros nestas cores). Na prática este sistema funciona por projeção e foi utilizado pelos primeiros processos fotográfcos em cor. As placas foram produzidas até $1935^{5}$ quando processo de cor cromogénica as veio substituir (Lavédrine \& Gandolfo, 2009).

O processo consistia num finíssimo mosaico de partículas transparentes formadas por grãos microscópicos à base de amido de batata, coloridos de roxo, vermelho e verde (c $0,015 \mathrm{~mm}$ ), pelos quais a luz refletida devia passar antes de impressionar a película fotossensível. A estrutura laminar da placa do autocromo era composta por um suporte em vidro onde se sobrepunham uma primeira camada de verniz misturado com borracha natural que permanecia aderente por forma a conter a camada de grãos de fécula de batata tingidos de vermelho-laranja, verde e azul-violeta que compunham o ecrã de cor. Os grãos eram pressionados numa prensa de forma a tornarem-se achatados e mais transparentes; para

5) Os Lumière produziram, ainda em 1931, o Filmcolor e, em 1933, o Lumicolor. Ja em nitrato de celulose, estes suportes eram mais rapidos tinham maior detalhe e erand De cobrir os interstícios entre os grãos de fécula era aplicado pó de carvão. Seguia-se uma segunda camada de verniz, sobre a qual era aplicada uma emulsão fotográfica de gelatina e prata pancromática que compunha a camada fotossensivel

As placas autochrome eram produzidas exclusivamente pela empresa Lumière et Ses Fils, e vendidas prontas a expor num câmara fotográfica comum. A placa era colocada com o vidro na direção do objeto a fotografar, para que a luz fosse registada na emulsão filtrada através do ecrã de cor Durante a exposição, os grãos coloridos do ecrã de cor funcionavam como filtros. Ao fotografar, por exemplo, um objeto verde, a luz verde refletida do objeto passa através dos grãos de fécula tingidos de verde e afeta a emulsão. No final, após a revelação, era aplcada uma camada de verniz (Cassela, 2011) que contribuia para uma imagem mais saturada e transparente, aumentandade média, necessitando sempre de uma câmara com tripé e de um filtro amarelo.

A visualização correta de uma placa autochrome é feita do lado da emulsão. As placas eram visualizadas por luz transmitida, usando um diascópio ou pendurando as placas numa janela, ou por luz projetada, recorrendo a uma lanterna mágimeios-tons ca. Podiam ser reproduzidas por processos fotomecânicos de

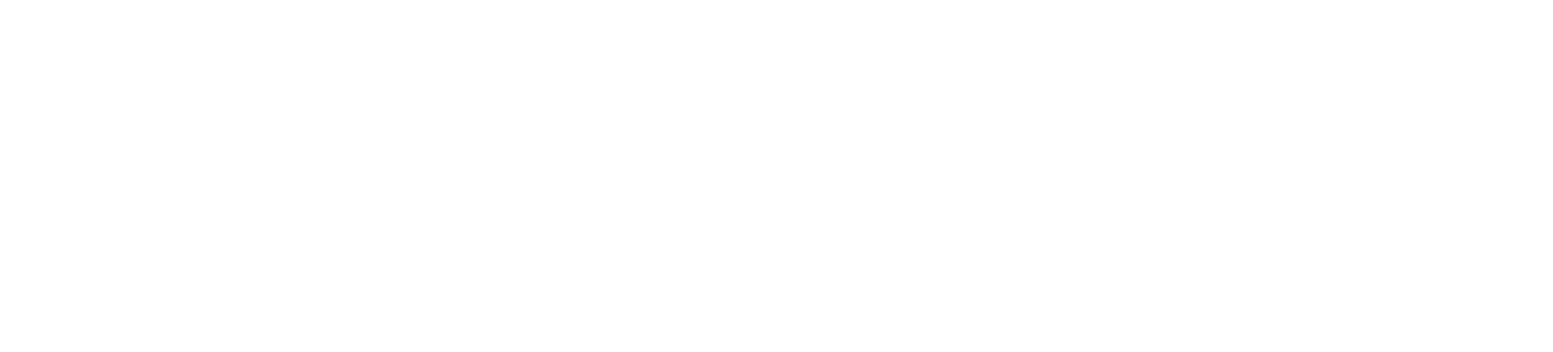

Fig. 11. Stereo-autochrome: Parc de Versailles
(Coleção de M. Peres)

Os autocromos na Medicina

Em 1901, os irmãos Lumière e o Prof. Léon Bérard, com quem tiveram uma longa colaboracão, apresentaram na Academia de Ciências de Paris a comunicação "De la photographie en couleurs - procédé de MM. Auguste et Louis Lumière - appliquée aux sciences médicales", sendo esta a primeira publicaçâa conhecida sobre a importância da produção e da utilização de fotografias médicas a cores Referem como vantagem a possibilidade de reproduzir especímenes anatómicos, microscópicos e histológicos, levando a um desenvolvimento do estudo da bacteriologia e da embriologia. Reconhecem ainda, a sua importância no ensino da medicina (Lumières \& Bérad, 1901). Em 1908, os médicos Regaud, Dubreuil e Louis (este

Fig. 10. Louis Lumiere com microscopio e tubos de ensaio, ca 1910 House (domínio público)
Hocromo $78 \times$. F

Também as imagens estereoscópicas coloridas (autocromos estereoscópicos) foram muito populares no início do século XX (Fig. 11) último diretor do serviço fotográfico da Universidade de Lyon) apresentaram 20 projeções de fotografias a cores em placas autochrome. Muitas representavam ovários de coelhas com uma ampliação de 150 a 800 vezes 
"'Os autores fazem notar a grande importância que o processo dos Senhores Lumière pode e deve ter para a fotografia aplicada às ciências anatómicas, e a incomparável superioridade deste processo em relação à fotografia a preto e branco que de preparaç̃oes histológicas' " (Regaud et al, 1908, p. 171).

Para fazer fotomicrografias em placas autochrome, os autore aconselhavam que se usasse $o$ arco elétrico como fonte de iluminação, e ainda um filtro amarelo. Embora este processo permitisse pela primeira vez a obtenção de fotomicrografias a cores, os tempos de exposição eram demasiado longos, ou seja, cerca de 5 minutos (Hind \& Randles, 1913). Em 1910 o oftalmologista V. Morax projetou várias fotografias a cores do olho na Société d'Ophtalmologie de Paris. Já em 1913, o médico Maitland Ramsay projetou uma série de fotografias a cores do olho durante o International Congress of Medicine (secção de Oftalmologia). A média sensibilidade das placas do autocromo implicava uma iluminação forte e um tempo longo de exposição, o que no caso da oftalmologia se tornava um problema (Fig. 12). Era necessário usar um filtro especial colorido para a luz de magnésio, pelo que era colocada uma lâmpada com um vidro protetor junto à face do paciente.

Maurice Letulle (1853-1929). médico e professor de Anatomia Patológica na Faculde de Medicina de Paris, publicou em 1916 o primeiro atlas sobre tuberculose, ilustrado com 107 autocromos (reproduções fotomecânicas) (Fig. 13). Ainda na

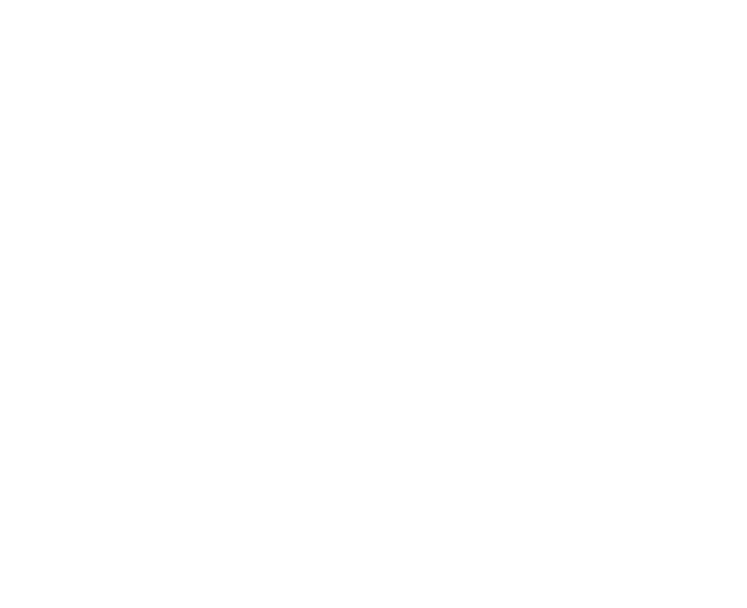

Fig. 12. Fotografias do olho (reproducão de autocromos)

do Instituto Pasteur Léon Albert Calmette (1863-1933) pub cou em 1920 "L' Infection Baccilaire et la Tuberculose chez I" Homme et chez les Animaux». Este volume contém 25 placas coloridas exibindo pinturas de Millot obtidas através dos autocromos do autor (Fig. 14). Um outro caso merecedor de destaque é Eugene-Louis Doyen (1859 - 1916), um dos Clrurgiões mais famosos do seu tempo e o primeiro a ter as suas cirurgias gravadas em filme. Doyen utilizava a imagem cinematográfica para fins pedagógicos, de modo a melhorar o seu desempenho e o da sua equipa. Trabalhou com os operadores de câmara Clément Maurice (que usava um cinematógrafo Lumière) e Parnaland que usava uma câmara de sua autoria (Baptista, 2005)

6) Para além de alguns exemplares existentes em arquivos franceses (foi produzido um filme pela "Cité des Sciences et de l'Industrie" em 2009) acredita se, que a maior parte da sua coleçao de pilaçoes com 10 filmes individuais que se terão realizado em 1906 e 1911 (Baptista, 2005). Um destes filmes foi exibido durante a exposição
"Corpo. Estado, Medicina e Sociedade no tempo da I República" que teve lugar em 2010, em Lisboa.

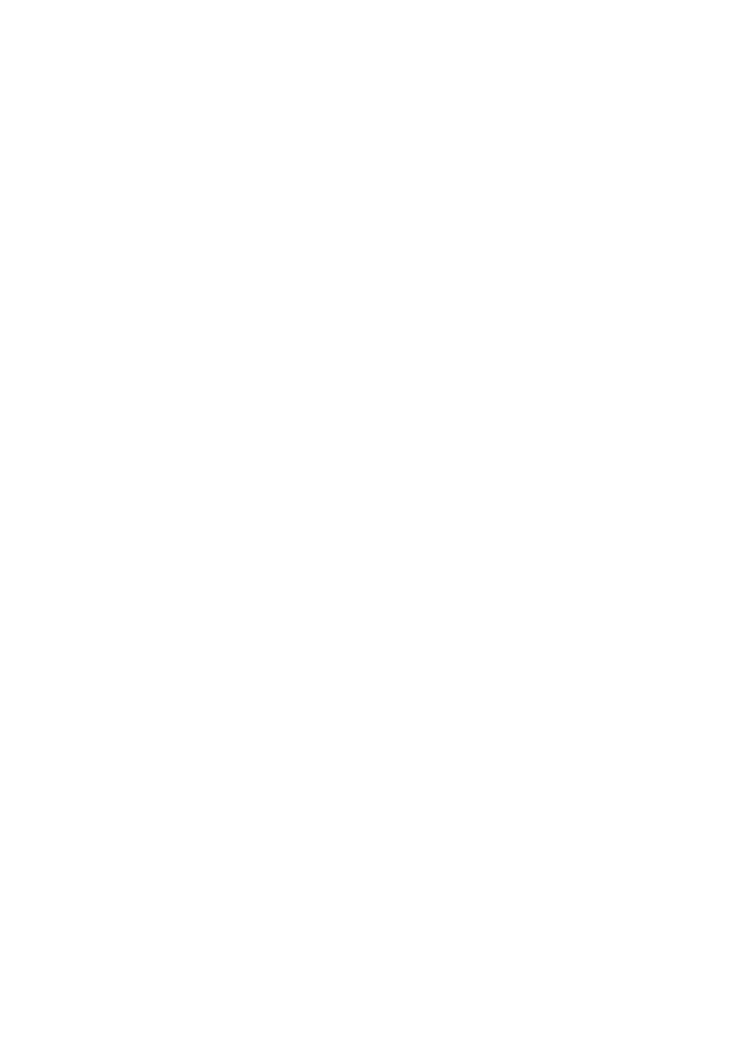

Fig. 13. Tuberculose nodular (autocromo de M. Letulle, reproduzido por tricomia) (Letulle, 1916)

Em 1910, Doyen iniciou a publicação dos "Archives de Doyen Revue médico-chirurgicale illustrée" onde eram reproduzidas fotografias que ilustravam momentos das cirurgias que realizava com a sua equipa (Fig. 15 e 16). No n. ${ }^{\circ}$ de 1911, apresenta a reprodução de quatro autocromos (Fig. 17), referindo

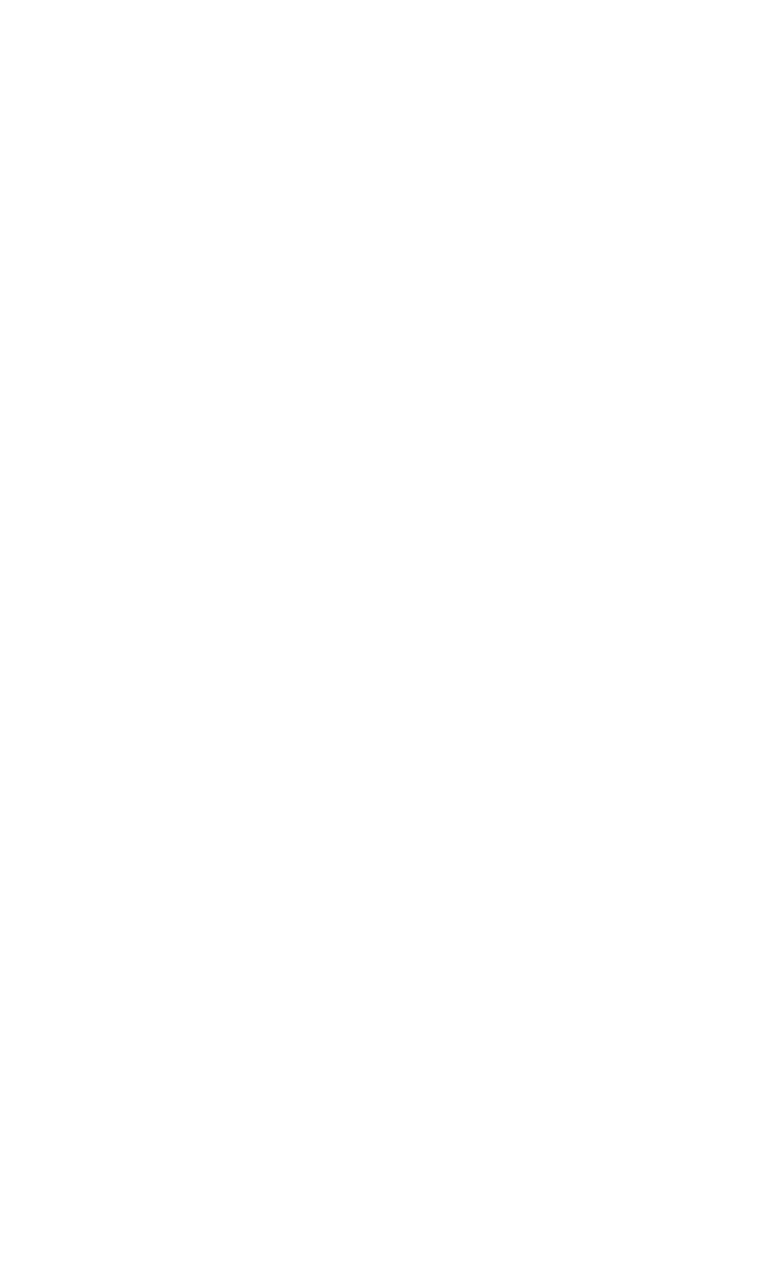

no artigo onde explica o processo, ter produzido 700 clichés (Doyen, 1911).

Em Portugal, o Instituto Bacteriológico foi criado em 1892 e foi também nesse ano que o jovem médico Câmara Pestana 
(1863-1899) associa a investigação ao ensino, lecionando noções práticas de Microbiologia no curso da 12. ${ }^{\text {a cadeira- }}$ Patologia Geral, Semiologia e História da Medicina - na Escola Médico-Cirúrgica de Lisboa, regida pelo Prof. José Thomas de Souza Martins (1843-1897). O Real Instituto Bacteriológico é inaugurado, após a morte de Câmara Pestana, em 1902, tendo recebido o seu nome. Esta instituição, que teve um papel primordial na Saúde e Higiene Pública (Gonçalves, 2006) possuía laboratórios equipados para investigação e ensino bem como um atelier de fotografia. É possível encontrar no espólio do Instituto Bacteriológico Câmara Pestana alguns autocromos com doentes de dermatologia (Fig. 18 e 19). Embora não estejam identificados, acredita-se terem sido feitos

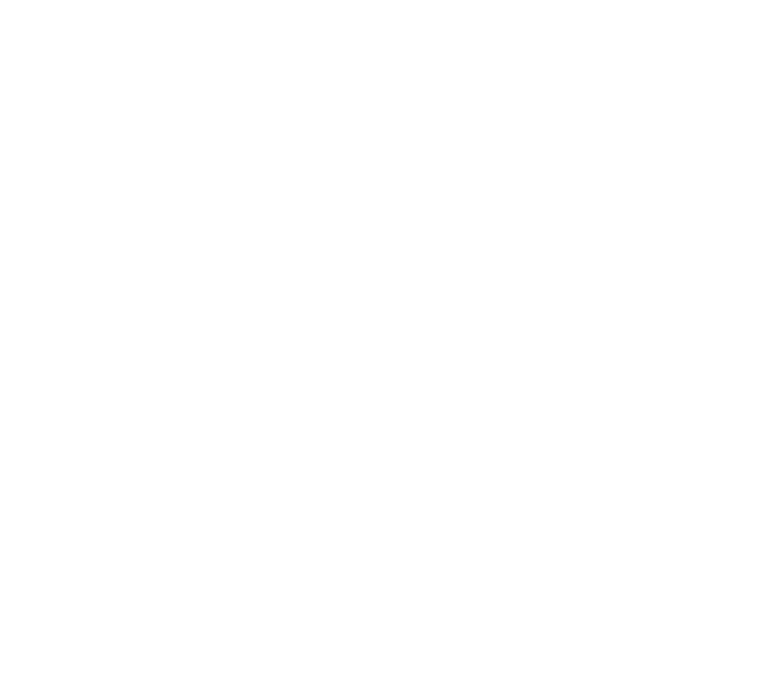

Fig. 15. Dispositivo usado para fotografar em placas autochrome -
tela protege o paciente da lâmpada de magnésio (Doyen, 1911, fig. 27) no atelier de fotografia deste instituto pois estão acondicion nos com fotomicrografias encontradas em publicacos desta stituição.

No espólio do Arquivo Histórico do Instituto Nacional de Med cina Legal - delegacão de Lisboa (INML - Lx), existe também um conjunto de seis autocromos que documentam um caso policial. Este caso corresponde ao homicídio de uma jovem mulher em 1912 (Fig. 20 e 21). Os exemplares apresentam-se já bastante degradados, necessitando de uma intervenção de conservação (Peres, 2013).

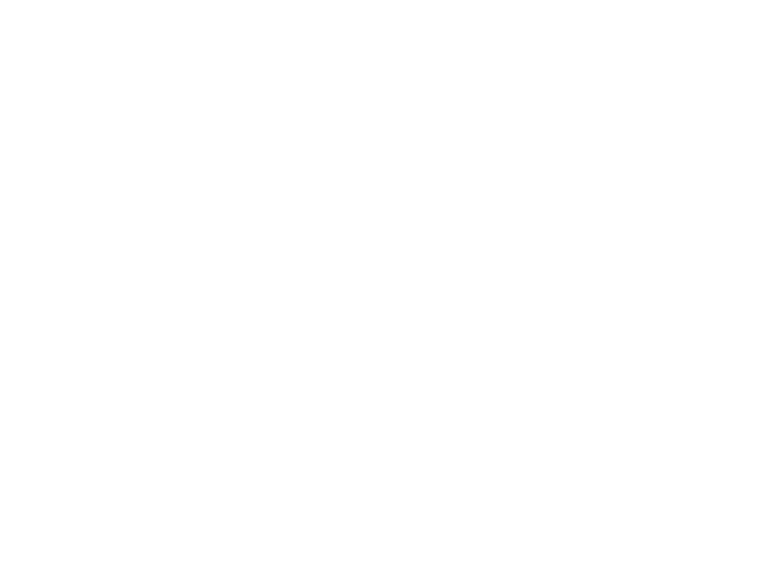

Fig. 16. Dispositivo para fotomicrografia em placas autochrome (Doyen, 1911, fig. 28)

\section{Considerações finais}

Apesar de se poder considerar que os dois processos são lusões, uma vez que a estereoscopia (a preto e branco esso autochromel mpressão de profundidade ou cor natural (Timby, 2005), eles tiveram um papel muito importante no desenvolvimento do

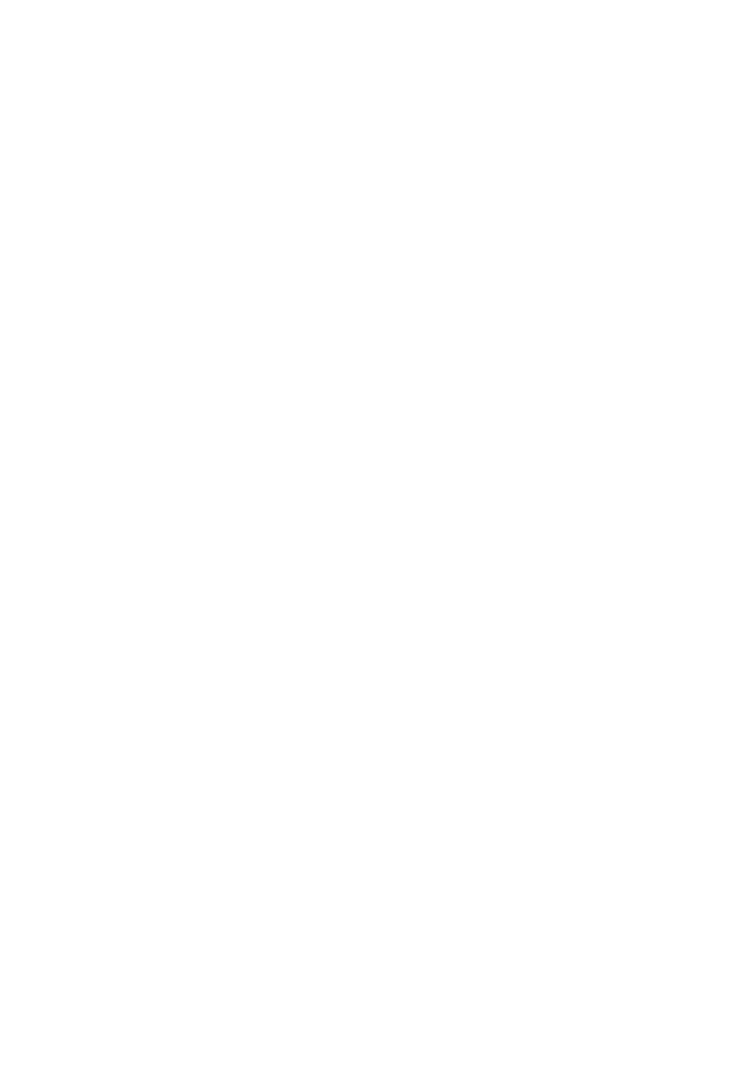

Fig. 17. Cirurgia da carótida pelo processo do Dr. Doyen (reprodução fotomecânica de um autochrome (Doyen, 1911, estampa XVIII) ensino e da prática médica No caso do processo autochrome principal vantagem está relacionada com o facto de a informação cromática poder ser muito boa. Do ponto de vista da medicina esta informação é muito relevante. Embora seja uma técnica com um processo de relevação relativamente simples, o facto de as suas placas não serem muito sensiveis obrigava sempre à utilização de um câmara fotográfica com suporte e tempos de exposição que eram cerca de 10 a 100

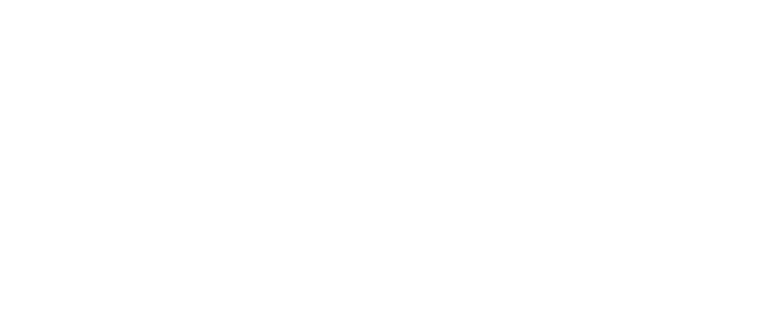
Fig. 18 e 19. Fotografias de pacientes de dermatologia em placas utochrome (Arquivo Histórico MUHNAC - coleção do Instituto

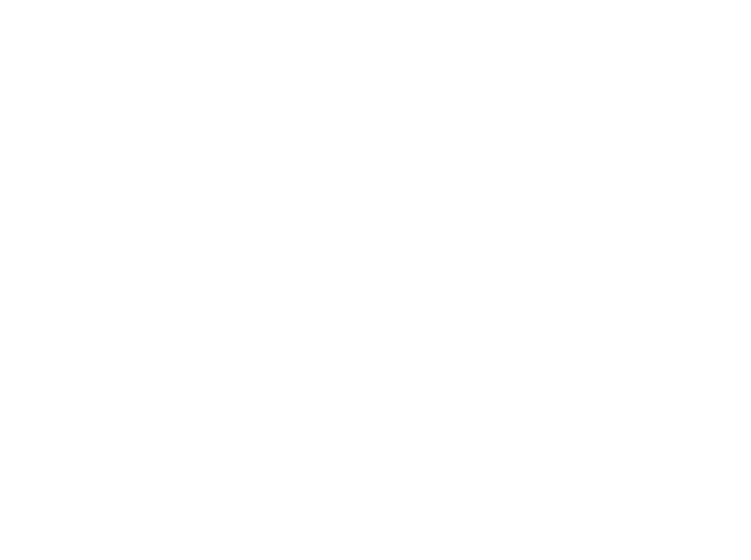

Fig. 20 e 21. Autocromos de um cadáver de uma mulher (de frente e perfil). caixa 2 - processo M. (cortesia do Arquivo do INML-Lx) 
vezes mais longos do que com placas para fotografia a preto e branco. 0 preço destas placas era também mais caro.

Os autocromos eram exemplares únicos e apesar de ser possivel a sua reprodução com processos fotomecânicos, dificilmente estes teriam um padrão cromático semelhante ao original. 0 modo de visualização dos autochromes também tinha limitações: ou necessitavam de um aparelho próprio ou tinham de ser projetados. Por outro lado, para visualizar os autocromos era necessário usar uma fonte de luz seme Ihante à luz usada durante a exposição, caso contrário, as cores teriam uma aparência diferente. A projeção, embora muito útil em congressos científicos e em aulas, tinha a desvantagem de tornar visivel, na ampliação, os grãos dos filtros e a luz necessária para a projeção promover os processos de foto oxidação, podendo destruir muito rapidamente as placas. Apesar de terem tido um pico de utilização nas duas primeiras décadas do século $\mathrm{XX}$, este processo foi substituído nos anos trinta por processos com suporte em nitrato de celulose, mais rápidos, com maior detalhe e de mais fácil revelação.

No caso da estereoscopia, pode ser referida como principal vantagem, o facto de ser uma técnica imersiva, que permite visualizar os objetos fotografados do modo mais natural para o cérebro, tendo sido por isso, muito útil para médicos e estudantes de medicina. A grande sensibilidade atingida pelas placas fotográficas (processo fotográfico de gelatina brometo de prata) no final do séc. XIX permitia tempos de exposição curtos, levando a grande desenvolvimento em várias áreas. como por exemplo a fotomicrografia.
A fotografia estereoscópica desapareceu do quotidiano das populações, sendo substituída pela imagem plana bidimensional. Para tal terá contribuído o aparato necessário à sua visualização, a subjetividade da imagem estereoscópica ou mesmo a sua utilização na indústria pornográfica. Além disso, como acrescentou Peixoto (2015), a fotografia estereoscópica não conseguiu o seu reconhecimento como objeto artístico. Apesar de não ter vingado na arte, na ciência podemos dizer que ganhou raízes. 0 facto de ser uma técnica imersiva obriga o cientista, o técnico ou o mero observador a construir uma imagem única no seu cérebro que não existe, tornando-se o observador parte do processo (Reis, 2010). Ao mesmo tempo que imerge na imagem fotográfica, o observador desliga-se do mundo exterior, focando-se apenas no objeto em estudo. Esta técnica continua a permitir visualizar objetos que não são diretamente percecionáveis com os nossos olhos, como no caso da fotomicrografia ou da radiografia. Contudo estas técnicas por si só não permitem a percecão tridimensiona sendo esse o importante papel desta técnica. Impressa en papel ou em formato digital a fotografia estereoscópica continua a ser uma das ferramentas da ciência mais importantes nos nossos dias.

\section{Agradecimentos}

A autora agradece o financiamento da Fundação para a Ciência e a Tecnologia por meio do Centro de Química Estrutura / CQE - Ciências da Universidade de Lisboa (PEST/OE/QUI/ U1700/2013); ao Arquivo Histórico do Museu Nacional de HisNacional de Medicina Legal - delegação de Lisboa

\section{Referências}

Abreu, J. (2007). Os estudos anatômicos e cirúrgicos na me dicina portuguesa do século XVIII. Revista da SBHC, 5(2), 149 172.

Baptista, T. (2005). II faut voir le maitre: A Recent Restoration of Surgical Films by E.-L. Doyen (1859-1916). Journal of film preservation, 70, 42-50.

Brewster, D. (1856). The stereoscope: Its History, Theory, and Construction, with Its Application to the fine and useful arts and to education. London: John Murray.

Calmette, L. (1920). L' Infection Baccilaire et la Tuberculose chez I' Homme et chez les Animaux. Paris: Masson et Cie, Éditeurs.

Cassela, L. (2011). Behavior of Autochrome Color Screen Dyes Under Anoxic Conditions. Topics in Photographic Preservation $14(11), 52-58$

Cheron, A. (1915). Les Procédés photographiques en ophtalmol ogie, Tours: Imprimerie E. Arrault et Cie.

Claudet, L. (2008). Stereoscopy. In Hannavy, J. (Ed.), Encyclopedia of Nineteenth-Century Photography (pp. 1338-1341) New York, London: Routhledge.

Cullen, T. (1943). Howard A. Kelly and Max Brodel. Baltimore Maryland: The Johns Hopkins Alumni Magazine.
Davanne, L-A. (1893). Invention et Applications de la Photographie, conférence du 22 Novembre 1891. In: Métiers CNdA (Ed.), Conférences publiques sur la photographie, organisées en 1891-1892 (pp. 1-29). Paris: Gauthier-Villars et Fils.

Davidson, J. M. (1898). Remarks on the value of stereoscopic photography and skiagraphy: records of clinical and pathological appearances. Br Med J., 2(1979), 1669-71.

Davidson, J. M. (1916). Localization by X rays and stereoscopy. London: H. K. Lewis

Doyen, E.-L. (1911). Service de photographie du Dr. Doyen. A chives de Doyen. Revue médico-chirurgicale illustrée, 5, 260-273

GE Healtcare (Ed.) (n.d). X-Rays and GE Innovation in Radiological Imaging, disponivel em http://newsroom gehealthcore. $\mathrm{com} / \mathrm{x}$-rays-and-ge-innovation-in-radiological-imaging/, consultado a 20/8/2015

Gernsheim, A. (1961). Medical Photography in the Nineteenth Century. Medical and Biological Illustration, 2, 85-92 e 3, 147

Gonçalves, R. (2006). Câmara Pestana e a Farmácia Porttguesa. In Pereira, A. \& Pita, J. Miguel Bombarda e as singulartdades de uma época (pp. 203-206). Coimbra: Imprensa da Un versidade de Coimbra.

Hind, H. L. \&. Randles, W. (1913). Handbook of Photomicrogra phy. New York: E. P. Dutton. 
Holmes, O (1859). The Stereoscope and the Stereograph. The Atlantic Monthly, 6, 738-48.

Judge, A. W. (1935). Stereoscopic photography. 2nd ed. London. Chapman and Hall Lda.

Kassabian, M. (1904). The value of stereoscopic skiagraphy with practical demonstration. New York Medical Journal (and Philadelphia Medical Journal), LXXX (27), 1249-53.

Kassabian, M. (1910). Röntgen rays and electro-therapeutics with chapters on radium and phototherapy Philadelphia \& London: J.B. Lippincott Company.

Lavédrine, B. \& Gandolfo, J.-P., (2009). L' Autochrome Lumière Secrets d'ateliers et défis industriels. Paris: CTHS.

Lavédrine, B. \& Gandolfo, J.P. (1993). Historical and Technical Investigation of the Autochrome Process and Attempts at Re-creation. Topics in Photographic Preservation, 5, 138-145.

Lavédrine, B., et al (2005). Coatings on Autochrome Plates. Coatings on Photographs: Materials, Techniques and Conservation. Washington, D.C.: Constance McCabe

Letulle, M. (1916). La tuberculose pleuropulmonaire. Paris: A. Maloine Et Fils, Editeurs.

Lumière, A., Lumière, L. \& Bérard, L. (1901). De la photographie en couleurs - procédé de MM. Auguste et Louis Lumière appliquée aux sciences médicales. Académie des Sciences de Paris (Dactylographié $18 \mathrm{p}$ )
Lumière A. Lumière, L.\& Seyewetz A. (1907). Sur le développement des plaques a tochromes, Bulletin de la Société Français de Photographie, 515-528

Monthus, A. (1908.). Iconographie stéréoscopique oculaire (anatomie clinique, technique opératoire). Paris: Mass

Neuse, W. et al (1966). The History of Photography in Dermatology: Milestones from the Roots to the 20th century. Arch Dermatology, 132, 1492-1498.

Peixoto, R. (2015). Como a vontade de ser arte da fotografia do final do século XIX expulsou a estereoscopia. Estudos em comunicação, 18, 39-52.

Peres, I. M. (2013). Fotografia científica em Portugal, das ori-

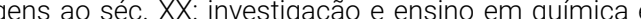
mencãa (tese de doutoramento). Lisboa: Universidade de

Peres, I. M. (2014). Processos fotográficos históricos. In: Cosa. F. \& Jardim, E. (coord.). 100 Anos de Fotografia Cientifica em boa: Edições 70

Peres, I. M. (2016). Aplicações da Fotografia Estereoscópica às Ciências: uma Perspectiva Histórica. In Flores, V. (ed.) Ste reo \& Immersive Media Proceedings 2015. Lisboa (pp. 22-50). Publisher: Lisboa: Ediç̃oes Universitárias Lusófonas.
Pombo, O. (2010). Introdução. In Pombo, O. \& Marco, S. (ed.) As imagens com que a Ciência se faz (pp. 9-20). Lisboa: Fim de Século - Edições.

Regaud, Dubreuil et Louis (1908). Utilisation de la photographie sur plaques autochromes (procédé de MM. Lumière) pour la documentation anatomique et histologique. Société médicale des hôpitaux de Lyon. Lyon medical, CXI, 171.

Reis, V. (2010). 0 fotógrafo estereoscópico: a descoberta da obra fotográfica de Francisco Afonso de Chaves (1857-1926). Revista: Estúdio, 1(2), 50-56.

Thomson, E. (1896). Stereoscopic Röentgen Pictures. Electr Eng, 21: 256.

Timby, K. (2005). Colour Photography and Stereoscopy: Paralel Histories, History of Photography, 29(2), 183-196.

Wheatstone, C. (1838). Contributions to the Physiology of Vision - Part first. On some remarkable, and Hitherto Unobserved, phenomena of binocular vision. Philosophical Transactions of the Royal Society of London, 128, 371-194. 